\title{
A produtividade da racionalidade neoliberal na inclusão escolar: a história de Lucas
}

\author{
Neusete Machado Rigo \\ Universidade Federal da Fronteira Sul (UFFS) \\ Maria Inês Naujorks \\ Universidade Federal de Santa Maria (UFSM)
}

Este artigo apresenta uma reflexão sobre o processo inclusivo de um menino com Transtorno do Espectro Autista (TEA). Quanto à metodologia, trata-se de uma abordagem qualitativa, utilizando-se da observação participante e de uma entrevista com questões abertas. A reflexão proporcionada por meio deste trabalho nos leva a compreender que as atuais políticas educacionais brasileiras, ao serem propositivas para a efetivação da inclusão das crianças com deficiências nas escolas comuns, ao mesmo tempo em que estão determinadas a garantirIhes o direito à educação, também não deixam de estar afetadas pelos propósitos do neoliberalismo na produção de sujeitos competitivos e empreendedores de si.

Palavras-chave: Inclusão escolar. Neoliberalismo. Capital humano. 


\section{The productivity of neoliberal rationality in school inclusion: the story of Lucas}

This paper presents and reflection on the inclusion process of a boy with Autistic Spectrum Disorder (ASD). As for the method, the approach is qualitative, using as instruments of data collection the observation of the participant and an interview. The reflection provided by this study lead to the comprehension that the current Brazilian educational policies, when proactive to the completion of inclusion of disabled children in regular schools, at the same time they are determined to guarantee the right to education, they are still affected by the purposes of neoliberalism in the production of competitive subjects and entrepreneur of themselves.

Keywords: School inclusion. Neoliberalism. Human capital.

\section{La productividad neoliberal racionalidad em la inclusón escolar: la historia de Lucas}

Em este artículo se presenta una reflexión sobre el proceso inclusivo de un niño con Trastorno del Espectro Autista (TEA). La metodología es un enfoque cualitativo, utilizando la observación participante y una encuesta con preguntas abiertas. La reflexión proporcionada por este trabajo nos lleva a comprender que las actuales políticas educativas de Brasil, proponen inclusión efectiva de los niños con discapacidad en las escuelas públicas, al tiempo que se determinan para garantizar su derecho a la educación, pero también no dejan de ser afectadas por los efectos del neoliberalismo en la producción de sujetos competitivos que invisten em si propios.

Palabras clave: Inclusión escolar. Neoliberalismo. Capital humano. 


\section{A inclusão escolar para além do direito}

O imperativo da inclusão propalado pela Política Nacional da Educação Especial na Perspectiva da Educação Inclusiva/2008 tem responsabilizado aos sistemas de ensino garantir a inclusão de todos nas escolas comuns, no ensino regular. $A$ inclusão escolar tem se tornado uma máxima inquestionável: precisamos incluir todos! Porém, não podemos compreender como ela se tornou uma questão tão presente nos dias atuais, sem considerar que o discurso da inclusão faz parte de uma razão de Estado que modifica, permanentemente, suas estratégias para manter suas forças de governamento sobre a população.

Para Foucault (2008), a partir do início do século XVII, o Estado desenvolveu uma arte de governar os homens segundo uma racionalidade própria, apresentando uma maneira de pensar o poder diferente do poder soberano que presenciamos até o final do século XVI. Um poder que não atua especificamente sobre os corpos, mas que tem, na captura da alma dos indivíduos e da população, o seu objetivo para o governamento e a condução destes e, assim, fortalecer e ampliar o poder do Estado. Um poder ocupado com a vida, com a preservação da vida e a segurança da população. Por isso, a inclusão pode ser uma estratégia para ampliar o governamento da população e, quanto mais esta se encontrar sobre o poder do Estado, menos problemas ele enfrentará para se manter.

A partir do século XX, vivemos uma razão de Estado mais articulada e produtiva entre o Estado e o mercado que Lopes (2009b, p. 167) define como cada vez mais agressiva e criativa. Nessa relação, o Estado adotou uma diversidade de táticas e dispositivos que visam garantir aos indivíduos condições mínimas de vida e de consumo, na forma de "investimentos para que a situação presente de pobreza, de falta de educação básica e de ampla miserabilidade humana talvez se modifique" (op. cit.), para que todos possam participar dos jogos do mercado e, desta forma, dar fluxo à lógica do capitalismo. Assim, o Estado, em parceria com o mercado, preocupa-se com questões relacionadas às condições básicas, essenciais para a vida das pessoas, regulando ou provendo àqueles mais carentes, por meio de políticas sociais. E é nesta lógica que podemos associar a inclusão escolar também como uma estratégia da razão de Estado neoliberal preocupado em colocar em funcionamento mais um dispositivo para manter sua integridade e ampliar as formas de governamento sobre a população.

Para que essa razão de Estado se mantenha, entram em funcionamento discursos que conduzem as populações; por isso, busca-se apoio nas noções foucaultianas para compreender o discurso da inclusão como um conjunto de enunciados que se apoia em uma mesma formação discursiva que acaba produzindo uma verdade (FOUCAULT, 2013). É neste sentido que a inclusão, ao mesmo tempo em que foi sendo construída no campo da educação mediante articulações, principalmente 
entre a Pedagogia e a Psicologia, também está envolvida por uma rede discursiva proveniente de diversos campos, tais como: dos direitos humanos, da mídia, das políticas governamentais, da legislação etc. São discursos permeados por relações de poder/saber que capturam as pessoas e vão produzindo a inclusão como uma verdade, por se utilizar de um "conjunto de procedimentos que permite a cada instante e a cada um pronunciar enunciados que serão considerados verdadeiros" (FOUCAULT, 2003, p. 233).

Declarações e documentos internacionais, políticas e normatizações nacionais são discursos oficiais que chegam às escolas, por intermédio dos órgãos gestores de ensino das instâncias federal, estadual e municipal, produzindo a necessidade da inclusão escolar. Nesse movimento de tensionamentos, constrói-se um contexto político-educacional com investimentos políticos, pedagógicos e financeiros para que as crianças com deficiências estejam matriculadas nas escolas comuns e não mais em escolas ou classes especiais. Os resultados disso aparecem nos dados estatísticos que apresentam, a cada ano, o aumento das matrículas das crianças com deficiências nas escolas regulares, o que nos leva a observar a efetivação das práticas da razão de Estado, que estão em funcionamento e interessadas em capturar essa população, para que participe mais ativamente das relações neoliberais contemporâneas entre Estado, mercado e educação.

Neste texto não queremos fazer uma análise sobre a importância ou a eficácia das políticas de inclusão, e sim discutir o que está presente no processo de inclusão escolar em uma sociedade como a nossa, em que os princípios do neoliberalismo afirmam-se cada vez mais em torno do aprimoramento do capital humano, corroborando uma razão de Estado. Nessa perspectiva, o homem deixa de ser sujeito de direitos, como podia ser nas sociedades modernas, passando a ser, na contemporaneidade, sujeito microempresa (GADELHA, 2013, p. 155). Um sujeito que não mais é visto simplesmente como produtivo para as exigências do capital, mas para, além disso, capaz de se tornar empresário de si, empreendedor de si e, por isso, competitivo. Como o "sangue que corre nas veias" e oxigena, a competição é a matriz que dá vida ao neoliberalismo contemporâneo.

Essa cultura do empreendedorismo, discutida por Gadelha (2013), explica-se pela disseminação da Teoria do Capital Humano que, no âmbito empresarial, propagase em "searas socioculturais, assistenciais e para aquelas propriamente educativas" (GADELHA, 2013, p. 154). Aproxima-se, sagazmente, da educação e faz dela mais um instrumento, entre outros, que, por sinal, pode ser muito eficiente para colocar em funcionamento o que Foucault (2006) chama de governamentalidade, ou seja, uma maneira de conduzir a todos "por determinadas práticas e regras implícitas que nos levam a entrar e permanecer no jogo econômico do neoliberalismo" (LOPES, 2009a, p. 109). As regras que organizam este jogo definem que todos devem participar, todos devem ser incluídos em um espaço de liberdade que lhes permitam desenvolvimento 
e aprimoramento de suas capacidades, embora essa participação não se dê em igualdade de posições. Por isso, faz-se necessário que todos sejam educados para entrar no jogo, que Ihes sejam proporcionadas condições para permanecer jogando e, ainda, o que é muito importante, que desejem permanecer nele (LOPES, 2009a, p. 110).

Nessa direção, a legislação educacional brasileira, embora justifique seus interesses na garantia do direito à educação, de certa forma atende a essa lógica, ao proclamar a "educação para todos". No entanto, é preciso deixar claro que a crítica que anunciamos aqui não se posiciona contrária à ampliação das condições da educação como direito social, nem tampouco contrária às políticas sociais atuais do Estado brasileiro. Mas sim, que se faz necessário empreender esforços para perceber os interesses do capitalismo e do mercado nas ações do Estado, a fim de colocar em funcionamento uma governamentalidade contemporânea.

Atualmente, temos uma Política Nacional de Educação Especial na Perspectiva da Educação Inclusiva que propõe aos sistemas de ensino o repensar da organização das escolas e das classes especiais, para que todos os alunos tenham suas especificidades atendidas (BRASIL, 2008, p. 9). Isso quer dizer que todas as crianças que possuam alguma deficiência, transtorno global de desenvolvimento ou superdotação podem estar na escola comum, e não mais em escolas ou classes especiais. Contudo, a esse imperativo faz-se necessária uma leitura mais atenta, para refletir sobre a existência dessa razão de Estado que colocamos em discussão e que, no contexto contemporâneo, orienta as políticas públicas de tal forma que todos estejam incluídos, evitando desvios que possam afetar a seguridade e o controle da população. Há, nas políticas públicas, um poder que está preocupado com o governo da vida de uma população; nessa relação situam-se, em específico, as pessoas com deficiências.

A discussão que propomos fazer aqui se aproxima do que Veiga-Neto (1995) chama de "hipercrítica", em uma perspectiva relacionada à desconfiança radical frente às verdades que estão presentes na operacionalização dos processos de inclusão na educação. Não para nos colocar contra ou a favor dela, mas para problematizá-la. Deste modo, para desenvolvê-la, trazemos um recorte sobre o processo de inclusão na escola comum, de um menino com Transtorno do Espectro Autista (TEA), que acompanhamos por um curto período, mas suficiente para fazer a crítica que nos propomos neste texto.

Empreendemos uma tentativa metodológica problematizadora de inspiração foucaultiana, envolvida em um exercício de liberdade, que James Marshall define como "o movimento pelo qual alguém se separa do que faz, de forma a estabelecêlo como um objeto de pensamento e, a refletir sobre ele como um problema" (MARSHALL, 2008, p. 31, grifo do autor). Assim, desenvolve-se um esforço para "instaurar uma distância crítica, de 'desprender-se', de retomar os problemas" 
(REVEL, 2005, p. 71), com um distanciamento necessário para que haja uma desnaturalização da realidade produzida durante o tempo em que estivemos acompanhando o processo de inclusão dessa criança.

Ainda, na tentativa de seguir a orientação de Marshall (2008, p. 31) para o exercício da problematização, atenta-se ao fato de que não se deve abordá-la "nem como adversário, nem como teórico ou ideólogo comprometido". Assim, fazemos as seguintes perguntas para desenvolver tal orientação: a) que efeitos produzem as representações do sujeito da educação especial presentes no processo de inclusão escolar? b) como podemos pensar as estratégias de inclusão escolar que, embora seja proclamada como um direito, também se encontra envolvida pela lógica do neoliberalismo?

Nessa direção, o corpus de análise do qual nos utilizamos consiste nos dados obtidos por intermédio da observação participante durante o ano de 2011, período em que estivemos em contato direto com o trabalho da Secretaria Municipal de Educação (SME) de um município da Região Fronteira Noroeste do Rio Grande do Sul, e também o relato de uma profissional que atuava nessa equipe.

\section{O direito à educação: a inclusão na escola comum}

Primeiramente, faz-se necessário contextualizar que as ações desenvolvidas pela SME encontravam-se em um momento bastante inicial do processo de inclusão na rede municipal de ensino. Aparentemente, a inclusão estava encaminhada no município, porque existiam convênios entre o poder público municipal e as escolas especiais prevendo cedência de professores e destinação de recursos públicos. Assim, em contrapartida, as escolas da rede municipal eram motivadas a encaminhar os alunos considerados "problemas" para a escola mantida pela Associação de Pais e Amigos dos Excepcionais (APAE), com o intuito de passarem por uma avaliação diagnóstica que, por meio de laudos médicos, definiria qual seu lugar: escola comum ou escola especial.

Isso começou a mudar com o desencadeamento de ações pela SME para atender à Política Nacional de Educação Especial na Perspectiva da Educação Inclusiva/2008, provocando a disseminação da inclusão nas escolas da rede municipal, de forma bastante incisiva. Mais ainda, quando chegou à SME, por encaminhamento do Conselho Tutelar, um menino de 9 anos, neste texto identificado como Lucas, que se encontrava fora da escola.

Lucas era um menino com autismo e tinha 9 anos. Apresentou um histórico de passagem na escola especial de surdos porque fora tido como surdo durante algum tempo; porém, em um dado momento, a escola, ao perceber que não era este o seu 
caso, solicitou seu desligamento e, assim, por meio do Conselho Tutelar, chegou à Secretaria Municipal de Educação acompanhado de diversos papéis, documentos e exames médicos de profissionais da saúde. Preocupamo-nos com a situação e chamamos os pais para conversar com a família para conhecê-lo melhor. Lucas veio acompanhando os pais e pareceu muito quieto, não falava e não respondia quando questionado, somente emitia alguns sons. A família explicava a situação do menino como decorrente de um afogamento no rio que teria sofrido por volta dos dois anos de idade. Para eles, até então, ele era um menino normal. A família não tinha compreensão do autismo. Ele foi tratado como surdo e ficou dois anos em uma escola de surdos. Por isso, fomos até esta escola, onde ouvimos um pouco da sua história: "ele chegou à escola como um bichinho [...]. Não parava, só corria, subia no vaso para fazer xixi, sem noção alguma" [...], e com esse quadro foram trabalhando com o menino (relato de uma professora). Por algumas vezes, faltava à escola, ligavam para a mãe e não tinham retorno. Então, foram até a casa e viram que ele estava sozinho em casa e os pais estavam trabalhando. Elas insistiram para conhecer o espaço da casa e aí se depararam com um espaço no quarto dos pais que tinha uma grade na porta que o impedia de passar e lá dentro tinha água. Ele vivia lá, enjaulado (segundo o relato que ouvimos da escola). Os pais moravam no interior e viviam da produção de hortifrutigranjeiros e como ficavam horas afastados da casa, lidando nos cuidados da plantação, desde pequeno o deixavam em casa sozinho e isolado, com provisão de comida e água para que se mantivesse bem até seu retorno, o que era visto pela agente de saúde como uma alternativa normal para a família cuidá-lo. Nós, enquanto equipe da SME, fizemos também várias visitas à família e pudemos constatar que sua condição de vida era de fato muito precária, vivendo em meio à sujeira, à falta de higiene, sem hábitos básicos, como, por exemplo, tomar água no copo, usar talheres e banheiro. Observamos que ele não sabia sentar no vaso sanitário e, por isso, defecava em qualquer lugar como um ato natural. Durante a visita que fizemos em sua casa, passou o tempo todo correndo e espantando os animais (que fugiam dele). Muito agitado, sem parar quieto, corria de um lado para o outro e só se aproximava e se acalmava quando a mãe lhe chamava usando tom de voz mais forte. Observamos, durante a visita, indícios da situação de privação relatada pelas professoras da escola especial, ao constatarmos ali uma cama sem lençóis e com um colchão sujo (relato de uma profissional da SME, 2011).

Essa realidade preocupou a equipe da SME e a levou a pensar que não seria possível matricular Lucas em uma escola comum, devido ao seu estado de "insociabilidade" e, então, dialogando com o Conselho Tutelar, a SME propôs, em audiência com o juiz da infância, que ele fosse matriculado na APAE, já que o município estabelecia convênios com a escola especial. Lá, talvez, estaria mais próximo dos seus "iguais". Participamos deste encontro, momento em que ouvimos da escola especial o argumento de que não poderia matriculá-lo "porque o seu Regimento Escolar não permitia atender crianças com autismo". A escola dos "anormais" não queria o "anormal". Se a escola comum não o queria, a escola especial também não.

Com a justificativa apresentada pela escola especial, transferiu-se ao poder público municipal a obrigação de garantir vaga ao menino em escola comum, situação que exigiu da equipe da SME pensar quais encaminhamentos seriam necessários e viáveis. Como não restava outra alternativa, porque a obrigatoriedade estava 
implícita, decidiu-se, então, conversar com a equipe diretiva de uma escola que ficava próxima da residência de Lucas. Participamos desse encontro, que se prolongou durante uma tarde inteira de diálogo e explicitação da situação para o "convencimento" da escola em aceitar a matrícula. De fato, o "convencimento" deuse em um jogo de poderes, em uma "ação de uns sobre os outros", porque, segundo Foucault (2006, p. 75), o poder "sempre se exerce em determinada direção, com uns de um lado e outros do outro; não se sabe ao certo quem o detém". Neste caso, a $\mathrm{SME}$, com seu poder institucional e legal, como autoridade sobre a escola e esta, submetida ao seu controle, "aceita" a matrícula do aluno, mediante o compromisso de a SME acompanhar e lhe dar o suporte pedagógico necessário, exercendo seu poder sobre a SME. Percebem-se, nessa relação, deslocamentos do poder, que ora está em um e ora em outro, exatamente como Foucault (2006) explica, pois ao mesmo tempo em que a SME exerce seu poder sobre a escola, a escola também o exerce, em um jogo em que um age sobre o outro, produzindo um "campo de respostas, reações, efeitos, invenções possíveis" (FOUCAULT, 1995, p. 243).

O poder não ocupa um lugar, "ele é um modo de ação de alguns sobre outros" (FOUCAULT, 1995, p. 242), ele passa pelos sujeitos, ele se transforma em ações. Assim, vemos que, ao mesmo tempo em que a SME, em um jogo de poderes entre ela, a escola especial e a justiça, sofre o poder, ao se sentir responsável pela promoção da inclusão do menino, também o exerce sobre a escola, que, aos poucos, vai sendo capturada pelo discurso da inclusão. Certamente, e não temos como observar, o poder continuará exercendo sua força produtiva nas relações internas da escola, entre a equipe pedagógica, a professora da sala de recursos, a professora da sala de aula comum, os alunos e as famílias. Isso porque o poder é ilimitável; ele age em feixes que se propagam sobre as ações dos outros.

Ele é um conjunto de ações sobre ações possíveis; ele opera sobre o campo da possibilidade onde se inscreve o comportamento dos sujeitos ativos; ele incita, induz, desvia, facilita ou torna mais difícil, amplia ou limita, torna mais ou menos provável; no limite, ele coage ou impede absolutamente, mas é sempre uma maneira de agir sobre um ou vários sujeitos ativos, e o quanto eles agem ou são suscetíveis de agir. Uma ação sobre ações (FOUCAULT, 1995, p. 243).

Assim, no primeiro dia em que o aluno foi a essa escola, a SME também estava lá.

No dia combinado em que a mãe e o menino viriam à escola para fazer a matrícula, acompanhamos a sua chegada e, em pouco tempo, percebemos o quanto foi desastrosa, pois ele ficou enlouquecido, muito agitado e descontrolado, não parava quieto e mexia em tudo, até fugir da sala em que estávamos e, correndo pelo pátio, apavorou mais ainda as professoras. Voltamos ao ponto zero [...]. Bom, ali não daria certo! (relato de uma profissional da SME, 2011). 
Essa tentativa frustrada de inclusão também não pode ficar à margem das relações de poder que estamos discutindo. Não deixa de estar aqui presente o poder do sujeito da educação especial no processo de inclusão que, ao sofrer o poder dos outros, exerce-o sobre estes outros, produzindo saberes e novas ações. As ações de Lucas, nessa relação de poder, levaram a equipe pedagógica "ao ponto zero" e provocaram a confirmação das representações que se tinha a seu respeito - uma criança dotada de impossibilidades e de incapacidades - tanto por parte da escola quanto pela SME. Trazer Lucas para a escola era algo de difícil aceitação, pois ele não estabelecia nenhuma relação social, nenhuma resposta ao que é "normal" na escola; seu comportamento era "antissocial" e, por isso, incomodava a todos - crianças e adultos. No entanto, outros saberes seriam produzidos, a partir dessa experiência de inclusão.

\section{As representações do sujeito da educação especial}

As relações de poder envolvidas nessa experiência provocaram a emergência de saberes sobre o processo de inclusão e também sobre o sujeito da educação especial, os quais serão discutidos tomando duas formas de representação que podem ser atribuídas a esse sujeito, sendo elas: a deficiência como estrangeiridade e como um peso para a sociedade.

Assim, pode-se iniciar essa reflexão situando Lucas como o estrangeiro, aquele que vinha de outro lugar, que falava (ou não falava!) outra língua, que estava fora do círculo cultural e, por isso, era também estranho. As escolas, acostumadas a uma determinada ordem, viam, na sua estrangeiridade, uma ameaça que colocava em risco a segurança na condução da vida de todos que compartilhavam os espaços da sala de aula e do pátio escolar. Isso tudo porque a desestabilização da ordem gera insegurança, além de fazer eclodir relações de poder/saber que ameaçam.

A deficiência fazia de Lucas o outro estrangeiro. Kohan (2007, p. 36) discute a experiência de ser estrangeiro/estranho/outro mexendo com a lógica de que "não há como ser estrangeiro sem ser estranho, assim como não dá para ser estranho sem ser outro", e também "não há como ser estrangeiro sem ser outro". Porém, essa convenção pode se alterar porque é possível "ser outro sem ser estranho, ser estranho sem ser estrangeiro e, muito mais fácil ainda, ser outro sem ser estrangeiro" (op. cit.). Lucas poderá não mais ser estrangeiro, após a escola - professores e colegas - desenvolver saberes capazes de proporcionar aproximação entre ambos, mas continuará estranho; e de estranho a outro, simplesmente, não há como saber.

As dificuldades para se tornar simplesmente outro podem ser intransponíveis, principalmente se considerarmos a racionalidade que atravessa essas relações de 
estrangeiridade. Bauman (1998) explica que nós, humanos, por sermos dotados de uma capacidade de aprender, só vemos benefícios em uma "boa organização". Nela prevalecem as noções de ordem e de pureza como elementos que compõem a racionalidade moderna e, por isso, "a chegada do estranho tem um impacto de um terremoto... O estranho despedaça a rocha sobre a qual repousa a segurança da vida diária" (op. cit., p. 19). Neste sentido, compreende-se que, matriculando o menino Lucas, a escola estaria abrindo mão de seu estado de "ordem" e de "pureza", como explica Bauman:

a pureza é uma visão das coisas colocadas em lugares diferentes dos que elas ocupariam se não fossem levadas a se mudar para outro, impulsionadas, arrastadas ou incitadas; e é uma visão da ordem - isto é, de uma situação em que cada coisa se acha em seu justo lugar e em nenhum outro. Não há nenhum meio de pensar sobre a pureza sem ter uma imagem da "ordem", sem atribuir às coisas seus lugares "justos" e "convenientes" - que ocorrem ser aqueles lugares que elas não preencheriam "naturalmente", por sua livre vontade. O oposto da "pureza" - o sujo, o imundo, os "agentes poluidores" - são coisas "fora do lugar" (BAUMAN, 1998, p. 14, grifos do autor).

A inclusão das pessoas com deficiências nas escolas comuns age como um mecanismo de afrouxamento à ordem que a escola procura manter. A escola tem dificuldades para perceber o que a configuração do contexto contemporâneo insiste em nos mostrar, ou seja, que o discurso da ordem está falido ou, pelo menos, não temos mais as certezas que o sustentavam. Embora, em geral, as escolas anunciem a diversidade e as diferenças como necessárias e/ou inevitáveis na sua organização curricular, não sabem muito bem como lidar com isso.

Assim, considerando o estado de ordem e de pureza que a modernidade tanto se preocupou em manter, pode-se dizer que este outro estrangeiro, o sujeito da educação especial (neste caso, o menino Lucas) poderia ser comparado a um "fardo social", tanto para a família quanto para o Estado. Lília Lobo (2008, p. 17) apresenta, em seu estudo "Os infames da história", sujeitos que foram tomados na história como infames "não porque seus feitos foram abomináveis", mas porque "foram considerados inválidos e incapazes de toda espécie". Em um exercício genealógico, a autora apresenta um conjunto de práticas, pertencentes ao contexto de quase 500 anos da história brasileira, que demonstra a representação dos pobres, dos escravos e dos deficientes considerados como fardos sociais "pesadíssimos tanto aos seus parentes como aos poderes públicos" (op. cit., p. 390).

Acompanhando a história escolar de Lucas e considerando o trabalho apresentado por essa autora, pode-se perceber alguma semelhança em relação à forma como se está operando hoje a inclusão. Poderíamos arriscar em dizer que a representação de Lucas como esse tipo de "fardo social" foi observável quando nem a escola especial nem a escola pública o queria como aluno, enquanto a família também via na escola 
a possibilidade de alívio.

A história mostra-nos o quanto a humanidade esteve preocupada com a sua segurança, controlando e isolando minorias indesejáveis e as colocando à margem, para evitar o perigo da desordem social. Se tomarmos a história dos povos indígenas, ciganos, negros, pobres e deficientes, em um exercício genealógico, como fez a pesquisadora Lília Lobo (2008), encontraremos práticas discursivas e não discursivas que se apresentam como acontecimentos, em temporalidades e espacialidades diferentes, mas que retratam um modo de pensamento muito similar.

Essas minorias, objetos de identificação e esquadrinhamento, produziram os estranhos, ou seja, aqueles que "não se encaixavam no mapa estético, cognitivo e moral" (BAUMAN, 1998, p. 27) hegemônico. Ainda segundo o mesmo autor, "o interesse pela pureza e a obsessão com a luta contra a sujeira emergem como características universais dos seres humanos" (op. cit., p. 16) e, assim, aqueles que são estranhos "são concebidos como um obstáculo para a apropriada 'organização do ambiente'; em que, em outras palavras, é outra pessoa ou, mais especificamente, uma certa categoria de outra pessoa, que se torna 'sujeira' e é tratada como tal" (op. cit., p. 17).

Se até o final do século XX o Estado liberal entendia as vantagens econômicas e sociais que existiam em separar os anormais porque "os capazes de progredir eram prejudicados" pela presença destes, se julgava ser um desperdício econômico os investimentos que poderiam ser destinados a essa população, da mesma forma conteve o acesso à educação às pessoas com deficiências. No entanto, na contemporaneidade intensifica-se uma racionalidade neoliberal que produz uma relação de absorção do estado pelo mercado que investe na inclusão de todos, com o propósito de diminuir o risco social que o "fardo social" poderia produzir, segundo a sua visão. Assim, se antes interessava ao estado liberal que as crianças com deficiências fossem para a escola especial e lá permanecessem, hoje é estratégico para o capital que elas estejam na escola de todos e de lá possam sair mais capazes, mais aptas a participar da grande teia que é o mundo sob os princípios neoliberais. Trata-se de uma atualização da roupagem da deficiência como "fardo social", que não deixou de existir como tal ou de assim ser considerada, porém agora, de outra forma, objetivada para ser produtiva.

A atenção com o risco social acompanha a humanidade desde a antiguidade, com as práticas eugenistas que se proliferaram, a partir do final do século XIX, estendendose até o século XX (LOBO, 2008). Estas práticas preocupavam-se com a vida, com a espécie humana, porém, desde que estivesse livre de "defeitos", tais como: a degenerescência, a pobreza, a negritude, a loucura etc. A eugenia - um projeto ideal de controle social do perigo na continuidade da espécie - estava atenta à degenerescência da raça humana, e tinha, na Medicina, seu suporte discursivo para construir práticas que, aos poucos, extrapolaram as instituições médicas e entraram 
primeiro nas famílias e, depois, nas escolas, espalhando-se por toda a sociedade (op. cit.). Ela estava incorporada a uma nova racionalidade para um Estado "mais adequado às novas relações capitalistas, econômicas e políticas" (op. cit., p. 110). Esta racionalidade de Estado queria evitar os efeitos que uma população marcada pela degenerescência causaria à espécie e à ordem social, pois ela representava uma ameaça para a continuidade do aperfeiçoamento da raça humana e também um perigo social, ao transformar essas pessoas em um "fardo social": "corpos inúteis para o trabalho, a pesar nas costas de toda a sociedade" (op. cit., p. 109).

Contudo, podemos pensar que as representações do sujeito da educação especial - a do "estrangeiro", que prejudica a ordem e a pureza das coisas, mas que pode ser normalizada; e a do "fardo social", que é um peso para a sociedade, mas que também pode se tornar produtiva - estão presentes no processo de inclusão na escola contemporânea.

Percebe-se que, na configuração do presente, há uma reatualização da ideia de "fardo social" em relação à pessoa com deficiência. Ela deixa de ser vista como um prejuízo aos demais, um peso porque não produz e, ainda, exige vigilância e um desperdício econômico (LOBO, 2008, p. 390), para ser um sujeito de investimentos econômicos e pedagógicos. Isso evidencia que, para o neoliberalismo contemporâneo, os sujeitos com deficiências não são vistos como um prejuízo à convivência com os demais; ao contrário, considera-se de grande importância que as crianças "normais" compartilhem o espaço da sala de aula com os "anormais", como forma de aprender a conviver com as diferenças; aposta-se e se investe na sua normalização para que se torne produtivo e conquiste espaço no mercado de trabalho, inclusive. Nisso tudo, há uma razão de Estado preocupada em "identificar o que é necessário e suficiente para que o Estado exista e se mantenha em sua integridade" (FOUCAULT, 2008, p. 344) e, ao fim e ao cabo, a inclusão das pessoas com deficiências na escola comum, a sua não exclusão, pode ser importante para evitar riscos à sua manutenção.

\section{A inclusão escolar envolvida por uma racionalidade neoliberal}

Da observação participante que se realizou junto ao trabalho da SME para efetivar a inclusão do menino Lucas, ficou evidente o compromisso e a responsabilidade do órgão municipal pela garantia do seu direito à educação. Nesse período, percebemos também que as representações do sujeito da educação especial como o "estrangeiro" e o "fardo social" estiveram presentes em vários momentos e, por isso, foram necessárias diversas tentativas e estratégias pela equipe da SME para que ela se

efetivasse. É por isso que, sem desmerecer esse esforço, queremos problematizar a inclusão escolar para além do direito e da ética, a fim de pensá-la pelo viés político 
para entender por que ela é tomada como uma política educacional tão importante no contexto contemporâneo.

Partimos do pressuposto de que as atuais políticas educacionais brasileiras, ao mesmo tempo em que se engajam na construção de estratégias e espaços para promover a inclusão social, não estão isentas dos efeitos de uma racionalidade neoliberal que está interessada na produção de sujeitos empreendedores de si, ou seja, sujeitos que cuidem das suas competências, que busquem aprimorarse e se especializar para ampliar as suas capacidades competitivas e, assim, consequentemente, intensificar e azeitar as engrenagens do capitalismo. Segundo esse pensamento, todos podem desenvolver-se de alguma forma, não importa qual, mas qualquer que seja essa capacidade produtiva, ela interessa ao neoliberalismo. Primeiro, porque assim o sujeito estará desejando participar dos jogos no mercado e, com isso, estará envolvido, diminuindo riscos de marginalização; segundo, porque sendo competitivo, estará investindo no seu capital humano, que é o novo espírito do capitalismo (GADELHA, 2009).

O investimento no capital humano é a prova de que não vivemos mais em uma sociedade somente do consumo e da mercadoria, e sim em outra, que aposta na concorrência e na competitividade. Muitos sociólogos discutem essa nova forma do capitalismo, explicando a Teoria do Capital Humano como um conjunto de capacidades, destrezas e aptidões dos homens que adquire "valor de mercado e se apresenta como forma de capital” (LÓPES - RUIZ, 2007, p. 18).

Esse espírito do capitalismo tem influenciado as políticas educacionais. Entre elas, pode-se situar a da inclusão escolar, quando objetiva normalizar o sujeito para que ele possa, na medida do possível, tornar-se um indivíduo produtivo. Ela está confirmando a educação para "todos" já anunciada no início do século XX, somandose a outras políticas de inclusão social. Desta forma, ninguém ficará excluído dos processos educativos e civilizatórios, nem mesmo aqueles sujeitos considerados "deficientes".

No entanto, esse contexto não se produz mediante ao acaso; há uma série de condições que se articulam para que a razão de Estado vá adquirindo novas versões e, por isso, reatualizando-se constantemente. Nada pode ser visto de forma natural e espontânea. Esse sujeito competitivo que interessa ao neoliberalismo contemporâneo é produzido por efeitos de poder da governamentalidade, "que busca programar estrategicamente as atividades e os comportamentos dos indivíduos [...] em suas formas de agir, sentir, de pensar e de situar-se diante de si mesmos, da vida que levam e do mundo em que vivem, através de determinados processos e políticas de subjetivação" (GADELHA, 2009, p. 178). Por isso, as políticas educacionais são tão importantes para o neoliberalismo. Elas são instrumentos desta governamentalidade em que a educação deve "funcionar como investimento, cuja acumulação permitirá não só o aumento da produtividade do indivíduo-trabalhador, mas também a 
maximização crescente dos seus rendimentos ao longo da vida" (op. cit., p. 177).

Há, nesse novo espírito do capitalismo, a produção de um sujeito que "não é o homem da troca, não é o homem consumidor, é o homem da empresa e da produção" (FOUCAULT, 2008, p. 201). Neste sentido, podem-se problematizar os processos de inclusão como estratégias dessa governamentalidade, que convencem as pessoas sobre a necessidade da inclusão, mobilizam novos saberes e produzem a esperança e o desejo pela inclusão. Isso nos leva a questionar: como a inclusão escolar participa desse novo espírito do capitalismo?

Para isso, precisamos compreender que, até o século XVIII, os deficientes, os degenerados e outros sujeitos considerados anormais viviam processos de uma "reclusão excludente", uma "prática que visava à limpeza pela exclusão daqueles apontados como indesejados" (LOPES, 2009b, p. 166), uma estratégia para livrar a sociedade do mal que a anormalidade representava. Porém, a partir do século XVIII, a "reclusão passa a ser matizada pelas práticas de inclusão" (op. cit., p. 166), e há uma aproximação das instituições que poderiam atuar produtivamente sobre estes sujeitos, de forma a recuperá-los pela inclusão. Chega-se então, a uma "reclusão includente", em que hospitais, escolas especiais ou reformatórios incluem estes sujeitos sob a alegação dos perigos e dos prejuízos que a sociedade teria ao mantêlos junto aos demais e que, por isso, faz-se necessário normalizá-los.

Diferentemente das sociedades disciplinares (séculos XVII e XVIII) preocupadas com a disciplina sobre os corpos e a docilização dos indivíduos, as sociedades de seguridade (a partir do século XIX), assim chamadas por estarem mais envolvidas com a segurança e a vida da população, estão interessadas em processos de normalização. Essa operação consiste em "tanto trazer os desviantes para a área da normalidade, quanto naturalizar a presença de tais desviantes no contexto social onde circulam - devem ser minimizadas certas marcas, certos traços e certos impedimentos de distintas ordens" (LOPES, 2009b, p. 160).

Por isso, a cada dia é possível perceber que a presença do sujeito com deficiência na escola comum (e na sociedade em geral), como definem as atuais diretrizes da educação especial, não é mais vista como anormal como há tempos atrás; ao contrário, o ingresso de crianças com deficiências nas salas de aula comuns passa a fazer parte de uma conduta considerada normal. Isso porque, na configuração neoliberal do presente, a inclusão passou a ser da ordem da normalidade.

Nesse sentido, a inclusão do menino Lucas passa pela sua aproximação à "normalidade" da sala de aula. Sua presença só poderia ser possível se trazido para a norma, pois no momento estava fora da "norma", mas não livre dela. Esta aproximação à norma implica noção de "normalização". Aqui, é importante trazer a explicação de Foucault (2008) sobre essas duas noções: normação e normalização. O primeiro processo decorre das disciplinas, característica das sociedades disciplinares, em que "partia-se de uma norma e era em relação ao adestramento efetuado pela norma que 
era possível distinguir depois o normal do anormal" (op. cit., p. 82). Era uma tentativa de conformar as pessoas em certos padrões constituídos previamente. Identifica-se esse conceito em ação, quando discutimos anteriormente as formas de exclusão e reclusão, quando aqueles que estavam fora da norma eram excluídos. Já, no segundo processo, o de normalização - característica da sociedade de seguridade -, invertese a posição da norma, ela não está mais a priori, mas é decorrente, ela é deduzida da relação entre normalidade e anormalidade. Primeiramente,

[...] vamos ter uma identificação do normal e do anormal, vamos ter uma identificação de diferentes curvas de normalidade, e a operação de normalização vai se constituir em fazer essas diferentes distribuições de normalidade funcionar umas em relação às outras e (em) fazer de sorte que as mais desfavoráveis sejam trazidas às que são mais favoráveis (FOUCAULT, 2008, p. 82-83).

No processo de normalização, a norma passa a ser aquilo que mais se aproxima da curva da normalidade, porque é a partir "do estudo das normalidades que ela se fixa e desempenha seu papel operatório" (FOUCAULT, 2008, p. 83). E, a partir dessa definição, estratégias de poder/saber entram em funcionamento para manter um grau de normalidade. De certa forma, Lucas estava fora da norma, ele não pertencia à normalidade dos alunos que estavam no $1^{\circ}$ ano do ensino fundamental, pois se encontrava acima da faixa etária para a série e não possuía uma conduta adequada para se introduzir nos esquemas cognitivos e sociais que são considerados próprios para as crianças da sua faixa etária. No entanto, ele é classificado como "recuperável", ou seja, "alguém merecedor dos investimentos do Estado" (LOPES; FABRIS, 2013, p. 211) para fazer parte na normalidade. Percebemos isso nos esforços que a SME empreendeu para lhe garantir a educação, não se restringindo à obrigatoriedade da sua matrícula na escola comum. Era visível a preocupação com as condições que Ihe assegurassem a permanência na escola (entre elas: o acompanhamento com a professora especializada, o transporte escolar, o atendimento com psicóloga, neurologista etc.). É o Estado investindo em Lucas para trazê-lo à norma, retirando-o da periferia:

[...] e recomeçamos o trabalho com outra escola, com outra professora na sala de recursos, mais receptiva, parecia que a situação poderia avançar, embora as demais professoras da equipe diretiva estivessem muito receosas. A escola improvisou uma sala de recursos para atender somente a ele, durante todos os dias, em quase a totalidade do período escolar com uma professora específica. Pensávamos que Lucas precisava socializar-se um pouco, aprender minimamente algumas coisas relacionadas à convivência para poder permanecer na sala de aula junto com os demais (relato de uma profissional da SME, 2011).

Diferentemente dessa escola, na primeira tentativa da SME para matricular Lucas, a escola sequer se propôs a "normalizá-lo". Tal como nos processos de normação das 
sociedades disciplinares, para a primeira escola, a norma está dada e quem não se identifica e não se enquadra nela, é excluído. Já para a segunda escola, a norma pode ser alterada, pode ser "alargada", desde que processos de normalização efetivem-se.

Nesse sentido, pode-se dizer que os processos de normalização interessam à racionalidade neoliberal do Estado contemporâneo, pois se tornando normal, o sujeito poderá desenvolver formas de competitividade - destrezas e/ou capacidades - que fazem com que adquira valor de mercado, sendo a "própria mercadoria num mundo de trocas e acumulação" (VEIGA-NETO, 2013, p. 5). Porém, não podemos "pensar que o neoliberalismo forma um todo homogêneo coeso e estável", como Veiga-Neto (op. cit.) nos alerta, ao dizer que ele é mais que ideologia e preceitos econômicos, é também uma forma de vida e de condução desta. Esta condução é a que percebemos nas políticas de inclusão que se orientam por uma racionalidade neoliberal que torna a escola comum, a instituição apropriada para fazer funcionar um processo de normalização pela inclusão escolar, porque ela "é o lugar privilegiado para a invenção e experimentação para novos saberes e para a intervenção do Estado e de suas políticas que visam à segurança da população" (VEIGA-NETO; LOPES, 2007, p. 957-958).

\section{Considerações finais}

Para finalizar, gostaríamos de retomar os propósitos deste texto, a fim de deixar claro que nossas intervenções nos processos de inclusão escolar não estão preocupadas em apresentar críticas às suas possibilidades de efetivação, mas estarmos atentas e, ao mesmo tempo, discutir com o(a) leitor(a) que as políticas de inclusão não estão livres das perversas estratégias neoliberais. As políticas educacionais brasileiras, por mais esforços que realizem para se afastar das malhas do mercado, estão, de certa forma, envolvidas por uma razão de Estado neoliberal que investe no aperfeiçoamento do capital humano. E, na configuração do presente, também as pessoas com deficiências são chamadas a participar, assim como outras minorias e culturas historicamente excluídas dos processos sociais, políticos, econômicas e culturais da sociedade.

No entanto, para que as condições de participação sejam dadas, não nos passa despercebido o investimento que o próprio Estado dispende por meio de uma política nacional de educação especial e seus desdobramentos nos estados, municípios e escolas. Quando esta política entra em funcionamento, saberes são produzidos em decorrência de relações de poder, principalmente em relação ao sujeito da educação especial que será envolvido por processos de normalização.

Por isso, ao mesmo tempo em que reconhecemos a inclusão das crianças com 
deficiências nas escolas comuns como uma possibilidade de educação, não se pode desconsiderar que a inclusão é um processo normalizador na esteira da governamentalidade neoliberal para a produção do capital humano. Pela inclusão, todos podem envolver-se ativos, produtivos e competitivamente nos jogos do mercado. Sendo competitivos, tornar-se-ão preocupados consigo, passarão a cuidar de si, investindo em si, e isso os retirará de uma condição de risco social, preocupação que acompanha o neoliberalismo, pois quanto menor for o risco social, menos serão os problemas sociais, tais como a fome, a miséria e a violência. Uma população educada, atendida nas necessidades que a vida exige, é uma população que apresenta baixos riscos sociais, por ser capaz de investir na melhoria de suas condições na família, no trabalho e nas relações sociais.

Por fim, espera-se que nossa tentativa de fazer uma discussão, a partir da história da inclusão de Lucas - uma experiência de inclusão vivida por sujeitos envolvidos na construção de uma política municipal de inclusão escolar - tenha provocado no(a) leitor(a) um olhar um pouco mais profundo a respeito do que pensamos e do que fazemos em relação aos processos de inclusão escolar.

\section{Referências}

BAUMAN, Zigmund. O mal-estar da pós-modernidade. Rio de Janeiro: Zahar, 1998.

BRASIL. Ministério da Educação. Secretaria da Educação Especial. Política Nacional de Educação Especial na Perspectiva da Educação Inclusiva. Inclusão, Brasília, v. 4, n. 1, p. 9-17, jan.-jun. 2008.

FISCHER, Rosa Maria Bueno. Foucault e a análise do discurso em educação. Cadernos de Pesquisa, São Paulo, n. 114, p. 197-223, nov. 2001.

FOUCAULT, Michel. O sujeito e o poder. In: RABINOW, Paul; DREYFUS Hubert. (Orgs.). Uma trajetória filosófica: para além do estruturalismo e da hermenêutica. Rio de Janeiro: Forense Universitária, 1995. 231-249.

. Poder e saber. In: MOTTA, Manoel Barros (Org.). Michel Foucault: estratégia, poder-saber. Rio de Janeiro: Ed. Forense Universitária, 2003. p. 223-240.

. Microfísica do poder. 22. ed. Rio de Janeiro: Graal, 2006.

. Segurança, território e população. São Paulo: Martins Fontes, 2008.

. A verdade e as formas jurídicas. 4. ed. Rio de Janeiro: NAU, 2013.

GADELHA, Sylvio. Governamentalidade neoliberal, teoria do capital humano e 
empreendedorismo. Educação e Realidade, Porto Alegre, v. 2, n. 32, p. 171-186, maio-ago. 2009.

- Biopolítica, governamentalidade e educação: introdução e conexões a partir de Michel Foucault. Belo Horizonte: Autêntica, 2013.

KOHAN, Walter. Um outro estrangeiro: entre a pedagogia e a educação; entre a polícia e a política. In: KOHAN, Walter. (Org.). Infância, estrangeiridade e ignorância: ensaios de filosofia e educação. Belo Horizonte: Autêntica, 2007. p. 35-56.

LOBO, Lília Ferreira. Os infames da história: pobres, escravos e deficientes no Brasil. Rio de Janeiro: Lamparina, 2008.

LOPES, Maura Corcini. Inclusão escolar, currículo diferença e identidade. In: LOPES, Maura Corcini; DAL'IGNA, Maria Cláudia (Orgs.). In/exclusão: nas tramas da escola. Canoas: Ed. Ulbra, 2007. p. 11-33.

. Inclusão como prática política de governamentalidade. In: LOPES, Maura Corcini; HATTGE, Morgana Domênica (Orgs.). Inclusão escolar: conjunto de práticas que governam. Belo Horizonte: Autêntica, 2009a. p. 107-130.

. Políticas de inclusão e governamentalidade. Educação e Realidade, Porto Alegre, v. 2, n. 34, p. 153-169, maio-ago. 2009b.

LOPES, Maura Corcini; FABRIS, Eli Henn. Inclusão e educação. Belo Horizonte: Autêntica, 2013.

LÓPES-RUIZ, Oswaldo. Os executivos das transnacionais e o espírito do capitalismo: capital humano e empreendedorismo como valores sociais. Rio de Janeiro: Azougue Editorial, 2007.

MARSHALL, James. Michel Foucault: pesquisa educacional como problematização. In: PETERS, Michael; BESLEY, Tina (Orgs.). Por que Foucault? Novas diretrizes para a pesquisa educacional. Porto Alegre: Artmed, 2008. p. 25-39.

REVEL, Judith. Foucault: conceitos essenciais. São Carlos: Claraluz, 2005.

VEIGA-NETO, Alfredo. Michel Foucault e educação: há algo de novo sob o sol? In: . (Org). Crítica pós-estruturalista e educação. Porto Alegre: Sulina, 1995. p. 9-56.

. Incluir para saber. Saber para excluir. Pro-Posições, São Paulo, v. 12, n. 2-3, p. 22-31, jul.-nov. 2001. Disponível em: <http://www.proposicoes.fe.unicamp.br/ proposicoes/edicoes/sumario24.html>. Acesso em: 27 maio 2015.

. Delírios avaliatórios: o currículo desvia para a direita ou um farol para 
o currículo. In: FAVACHO, André; PACHECO; SALES, Shirlei. (Orgs.). Currículo: conhecimento e avaliação: divergências e tendências. Curitiba: CRV, 2013. p. 155175.

VEIGA-NETO, Alfredo; LOPES, Maura Corcini. Inclusão e governamentalidade. Educação e Sociedade, São Paulo, v. 28, n. 100, p. 947-963, out. 2007. Disponível em: <http://www.scielo.br/pdf/es/v28n100/a1528100.pdf>. Acesso em: 27 maio 2015 .

Recebido em agosto de 2015.

Aprovado em novembro de 2015.

Neusete Machado Rigo é doutoranda em Educação no Programa de Pós-Graduação da Universidade Federal de Santa Maria (UFSM) e professora na Universidade Federal da Fronteira Sul (UFFS). Integrante do Grupo de Estudos e Pesquisa em Educação Especial (GEPE) da UFSM. Trabalha em cursos de licenciatura e atua na pesquisa e na extensão universitária em programas de formação de professores da educação básica. E-mail: <neuseterigo@gmail.com>.

Maria Inês Naujorks é doutora em Psicologia Social pela Universidade de São Paulo (USP) e professora titular do Departamento de Educação Especial da Universidade Federal de Santa Maria (UFSM). Credenciada no Programa de PósGraduação em Educação, na Linha de Pesquisa de Educação Especial. Lidera o Grupo de Estudos e Pesquisa em Educação Especial e Inclusão da UFSM e do Conselho Nacional de Desenvolvimento Científico e Tecnológico (CNPq). E-mail: <minau1990@gmail.com>. 